\title{
Knowledge and Practice of Mother regarding Exclusive Breastfeeding Having Infant at a Tertiary Level Hospital, Kathmandu
}

\author{
Adhikari TM ${ }^{1}$
}

\begin{abstract}
Introduction: Promotion of exclusive breastfeeding is a cost effective intervention to reduce infant mortality in developing countries. The objective of this study was to identify knowledge and practice of mothers regarding exclusive breastfeeding. Material and Methods: This was a descriptive exploratory study carried out in the immunization clinic of tertiary level hospital in Kathmandu. A total of 323 mothers who came for immunization of six months to one year were selected as the sample for the study by using non-probability purposive sampling technique. Semi - structured interview questionnaire was used to collect the data both on knowledge and practice of exclusive breastfeeding, from $13^{\text {th }}$ July to $8^{\text {th }}$ September 2014. Results: Study findings revealed that $84.5 \%$ of the respondents were aware of the correct meaning of exclusive breastfeeding and $49.5 \%$ of the respondents practiced exclusively breastfeeding to their children up to 6 months. There was statistically significant association of respondent's level of knowledge regarding exclusive breast feeding with their educational status $(p=0.034$, $\mathrm{OR}=1.7,95 \% \mathrm{Cl}=1.03-2.66)$ and type of delivery $(p=0.005$, $\mathrm{OR}=1.9,95 \% \mathrm{Cl}=1.2-3$ ). Likewise, a significant association was seen between respondent's level of practice regarding EBF and type of delivery ( $p=0.005, O R=1.9,95 \% \mathrm{Cl}=1.2-3$ ). Conclusion: Study concludes that only about half of the mothers tended to have adequate knowledge regarding exclusive breast feeding. However, practice of exclusive breastfeeding for up to six months tended to be low so there should be efforts on encouraging and counseling for exclusive breast-feeding up to six months in hospital, community and immunization clinic.
\end{abstract}

Key words: Exclusive Breastfeeding (EBF), Knowledge, Practice, Mother

\section{Introduction}

R reast milk is the natural first food for babies. It provides all the nutrients required by the infant for the first six months of life and it continues to provide up to half or more of a child's nutritional needs during the second half of the first year, and up to one-third during the second year of life ${ }^{1}$. Exclusive breastfeeding is one of the most cost effective interventions to reduce infant mortality. It is estimated that more than one out of every 10 infant-deaths (13\%) could be saved
'Ms Tulashi Adhikari Mishra, (MN in Child Health Nursing), Lecturer, Tribhuvan University, Institute of Medicine, Nursing Campus, Maharajgunj, Kathmandu, Nepal.

\section{Address for correspondence:}

Tulashi Adhikari Mishra (MN), Lecturer Tribhuvan University, Institute of Medicine Nursing Campus, Maharajgunj, Kathmandu, Nepal.

Email: tulsi 50@hotmail.com

Tel: +977-9841543782

\section{How to cite}

Adhikari TM. Knowledge and Practice of Mother regarding Exclusive Breastfeeding having Infant at a Tertiary Level Hospital, Kathmandu. J Nepal Paediatr Soc 2014;34(3):200-206.

doi: http://dx.doi.org/10.3126/jnps.v34i3.12107

This work is licensed under a Creative Commons Attribution 3.0 License.

(c) (i)

by promoting exclusive breastfeeding ${ }^{2}$. For almost all infants, breastfeeding remains the simplest, healthiest and least expensive method of feeding. Despite strong evidence in support of exclusive breast feeding (EBF) for the first six months of life; its prevalence has remained low worldwide ${ }^{3}$. Globally less than $40 \%$ of infants under six months of age are exclusively breastfed. Adequate breastfeeding support for mothers and families could save many young lives ${ }^{4}$.

Breastfeeding helps to prevent hypothermia and hypoglycemia in newborn 
babies, which are the commonest causes of early neonatal deaths especially among low birth weight and premature babies. During the late neonatal period, most deaths in developing countries occur due to infections such as sepsis, acute respiratory tract infection, meningitis and diarrhea. Feeding colostrums and exclusive breastfeeding protects against such deaths ${ }^{5}$.

According to Nepal Demographic and Health Survey Report ${ }^{6}$, Forty-one percent of children under five years of age are stunted, and 11 percent are wasted and 29 percent are under weight. Promoting exclusive breastfeeding up to six months of age to $88 \%$ by the end of 2015 and controlling protein energy malnutrition (PEM) are the major strategies of government of $\mathrm{Nepal}^{7}$. Therefore, protecting and promoting breastfeeding has been one of the important priorities of public health in Nepal.

In the conditions that normally exist in developing countries, exclusively breastfed children are six times more likely to survive in the early months than nonbreastfed children. Exclusively breastfed infants are six times less likely to die from diarrhea and 2.4 times less likely to die from acute respiratory infection in first six months of life ${ }^{8}$.

The aim of this study was conducted to identify knowledge and practice of exclusive breastfeeding (EBF) among the mothers having infants.

\section{Material and Methods}

This descriptive exploratory study was carried out after getting proposal approved by Institutional Review Board of the Institute of Medicine, Kathmandu and the Research Division of Tribhuvan University. Kirtipur Kathmandu. Permission to conduct the study in the immunization clinic was taken from the Tribhuvan University Teaching Hospital Director by submitting a written request letter of the Research Division, A semi-structured interview schedule developed for the study was pretested among 30 mothers (10\% of the estimated sample size) in the immunization clinic of Kanti Children's Hospital. Study sample consisted of total 323 who attended the immunization clinic for the immunization of their infants aged between 6 months to 12 months and who met the inclusion criteria. Data was collected by trained data collectors from July 13 to September 8, 2014.

The data were edited, classified, coded and entered into Statistical Package for Social Science
(SPSS) version 21.00. The data was analyzed by using descriptive statistics such as frequency, percentage and inferential statistical such as Chi-square test, odds ratio and Pearson's correlation.

\section{Results}

Table 1 reveals that the mean age of 323 respondents was $26.55( \pm 3.8)$. Likewise, Hindus comprised $92 \%$ of the respondents and $60.4 \%$ of the respondents belonged to Brahmin/ Chhetri ethnicity. In terms of education, majority (68.1\%) of the respondents had higher secondary level education. However, majority $(74.3 \%)$ of the respondents were housewives. Almost all (98.5\%) of the respondents had hospital delivery with vaginal delivery as $62.5 \%$ (Table 2).

Table 3 depicts knowledge of respondents and reveals that $84.5 \%$ of the responded were aware about meaning of EBF, $79.6 \%$ of the respondents were aware of initiation of breastfeeding as within one hour to a child after birth. Likewise almost all (99.1\%) respondents were aware that colostrums should be fed to the baby. Only $48.0 \%$ of the respondents gave EBF on demand.

Table 4 reveals that three-forth $(75.5 \%)$ of the respondents gave breastfeeding to their children within one hour and $79.9 \%$ of the respondents correctly avoided giving pre-lacteal feeding to the baby. Only $54.8 \%$ of the respondents gave breastfeeding to their infant on demand during the early months after delivery and $49.5 \%$ of the respondents practiced EBF up to 6 months.

Knowledge responses were scored and level of knowledge regarding EBF was categorized as high and low on the basis of median knowledge score percentage of 65.6. Knowledge score percentage of 65.6 and above was categorized as high level of knowledge and knowledge score percentage of below this was categorized as low level of knowledge. More than half (53.3\%) of the respondents had high level of knowledge regarding exclusive breast feeding.

Similarly, level of practice was also categorized as high and low on the basis of median practice score percentage that was 60 . Practice score percentage of 60 and above was categorized as high level of practice and practice score percentage of below 60 was categorized as low level of practice. More than half (59.4\%) of the respondents had high level of practice regarding exclusive breast feeding (not shown in the table). 
Table 5 reveals that there was a significant association between respondent's level of knowledge regarding EBF and educational status ( $p=0.034$, OR $=1.7,95 \% \mathrm{Cl}=1.03-2.66)$. High level of knowledge regarding EBF was found among the respondents with educational status of above SLC (47.3\%) than respondents with educational status of up to SLC (44.7\%). Table 6 indicates that a significant association was seen between respondent's level of practice regarding $\mathrm{EBF}$ and type of delivery $(\mathrm{p}=0.005, \mathrm{OR}=1.9$, $95 \% \mathrm{Cl}=1 \cdot 2-3)$. High level of practice regarding EBF was seen more among the respondents with vaginal delivery $(65.3 \%)$ than respondents with caesarian delivery (49.6\%). Table 7 shows there was week but significant correlation between knowledge and practice scores.

Table 1: Socio-demographic Characteristics of the Respondents ( $n=323$ )

\begin{tabular}{|l|c|c|}
\hline Socio-demographic Characteristics & \multicolumn{2}{|c|}{ Percent (\%) } \\
\hline Age (in years) & 136 & 42.1 \\
\hline $18-25$ & 149 & 46.1 \\
\hline $26-30$ & 32 & 9.9 \\
\hline $31-35$ & 6 & 1.8 \\
\hline$>35$ & $26.55( \pm 3.8)$ & \\
\hline Mean age (SD) & \multicolumn{2}{|c|}{} \\
\hline Religion & 297 & 92 \\
\hline Hindu & 16 & 5 \\
\hline Buddhist & 6 & 1.9 \\
\hline Muslim & 4 & 1.2 \\
\hline Christian & & \\
\hline Educational Status & 8 & 2.5 \\
\hline Illiterate & 16 & 5 \\
\hline Primary level & 79 & 24.5 \\
\hline Secondary level & 220 & 68.1 \\
\hline Higher secondary level & & \\
\hline Occupational Status & 240 & \\
\hline Housewife & 43 & \\
\hline Service & 30 & \\
\hline Business & 9 & \\
\hline Agriculture & & \\
\hline
\end{tabular}

Table 2: Place and Type of Delivery of the Last Childbirth among the Respondents $(n=323$ )

\begin{tabular}{|l|c|c|}
\hline \multicolumn{1}{|c|}{ Variables } & Frequency & Percent \\
\hline Place of Delivery & 318 & 98.5 \\
\hline Hospital & 5 & 1.5 \\
\hline Home & 202 & 62.5 \\
\hline Type of Delivery & 121 & 37.5 \\
\hline Vaginal & & \\
\hline Caesarian & & \\
\hline
\end{tabular}


Table 3: Knowledge Regarding EBF among the Respondents

\begin{tabular}{|l|c|c|}
\hline Correct Responses Knowledge Items & Frequency & Percent \\
\hline Meaning of EBF as feeding only breast milk & 273 & 84.5 \\
\hline Initiation of Breastfeeding as within one hour of delivery & 257 & 79.6 \\
\hline Prelacteal feeding should be avoided & 273 & 99.5 \\
\hline Colostrum should be given to the baby & 320 & 48.0 \\
\hline Frequency of EBF to be given as on demand & 155 & 76.2 \\
\hline Advantages of Breastfeeding to the baby as* & 246 & 71.2 \\
\hline Protection from infections & 230 & 13.3 \\
\hline Breast milk contains the right kinds of nutrients & & 10.5 \\
\hline Enhances brain development & 43 & 6.5 \\
\hline Easily digested & 34 & \\
\hline Enhances the emotional bonding & 21 & \\
\hline Advantages of Breastfeeding to the mother as*: & & \multicolumn{2}{|c|}{} \\
\hline Prevents breast and ovarian cancers & 126 & 39.0 \\
\hline Helps in delaying another pregnancy & 87 & 26.9 \\
\hline Convenient & 55 & 17.0 \\
\hline Reduces postpartum bleeding & 13 & 4.0 \\
\hline
\end{tabular}

*Multiple responses

Table 4: Practice Regarding Breastfeeding among the Respondents ( $n=323$ )

\begin{tabular}{|c|c|c|}
\hline Practice-related correct items & Frequency & Percent \\
\hline Initiation of breastfeeding as within one hour & 244 & 75.5 \\
\hline Pre-lacteal Feeding as not given & 255 & 78.9 \\
\hline Frequency breast feeding used as demand feeding & 177 & 54.8 \\
\hline Duration of Exclusive Breast Feeding as up to 6 months & 160 & 49.5 \\
\hline
\end{tabular}

Table 5: Association between Respondent's Level of Knowledge regarding EBF and Selected Variables $(n=323)$

\begin{tabular}{|c|c|c|c|c|c|c|}
\hline \multirow[b]{2}{*}{ Variable } & \multicolumn{2}{|c|}{ Knowledge Category } & \multirow[b]{2}{*}{$x^{2}$} & \multirow[b]{2}{*}{ OR } & \multirow[b]{2}{*}{$95 \% \mathrm{Cl}$} & \multirow[b]{2}{*}{$p$-value } \\
\hline & $\begin{array}{c}\text { Low } \\
\text { No. (\%) }\end{array}$ & $\begin{array}{c}\text { High } \\
\text { No. (\%) }\end{array}$ & & & & \\
\hline \multicolumn{7}{|l|}{ Age of the respondents } \\
\hline$\leq 25$ years & 67 (49.3) & $69(50.7)$ & \multirow{2}{*}{0.59} & 1.19 & $0.76-1.85$ & \multirow{2}{*}{0.44} \\
\hline$>25$ years & $84(44.9)$ & $103(55.1)$ & & & & \\
\hline \multicolumn{7}{|l|}{ Religion } \\
\hline Hindu & $139(46.8)$ & $158(53.2)$ & \multirow{2}{*}{0.04} & 1.03 & $0.46-2.29$ & \multirow{2}{*}{0.94} \\
\hline Others & $12(46.1)$ & $14(53.9)$ & & & & \\
\hline \multicolumn{7}{|l|}{ Occupation } \\
\hline Housewife & $118(49.2)$ & $122(50.8)$ & \multirow{2}{*}{2.19} & 1.46 & $0.88-2.43$ & \multirow{2}{*}{0.13} \\
\hline Others & $33(39.8)$ & $50(60.2)$ & & & & \\
\hline \multicolumn{7}{|l|}{ Educational Status } \\
\hline Up to Secondary level & $57(55.3)$ & $46(44.7)$ & \multirow{2}{*}{4.48} & 1.7 & $1.03-2.66$ & \multirow{2}{*}{0.034} \\
\hline Higher Secondary level & $94(42.7)$ & $126(47.3)$ & & & & \\
\hline \multicolumn{7}{|l|}{ Type of Delivery } \\
\hline Vaginal & $91(45)$ & $111(55)$ & \multirow{2}{*}{0.62} & 0.83 & $0.53-1.31$ & \multirow{2}{*}{0.42} \\
\hline Caesarian & $60(49.6)$ & $61(50.4)$ & & & & \\
\hline
\end{tabular}


Table 6: Association between Respondent's Level of Practice Regarding EBF and Selected Variables $(n=323)$

\begin{tabular}{|c|c|c|c|c|c|c|}
\hline \multirow{2}{*}{ Variable } & \multicolumn{2}{|c|}{ Practice Category } & \multirow{2}{*}{$x^{2}$} & \multirow{2}{*}{ OR } & \multirow{2}{*}{$95 \% \mathrm{Cl}$} & \multirow{2}{*}{$p$-value } \\
\hline & Low & High & & & & \\
\hline \multicolumn{7}{|c|}{ Age of the respondents } \\
\hline$\leq 25$ years & $55(40.4)$ & $81(59.6)$ & \multirow{2}{*}{0.001} & \multirow{2}{*}{0.99} & \multirow{2}{*}{$0.63-1.55$} & \multirow{2}{*}{0.97} \\
\hline$>25$ years & $76(40.6)$ & $111(59.4)$ & & & & \\
\hline \multicolumn{7}{|l|}{ Religion } \\
\hline Hindu & $115(38.7)$ & $182(61.3)$ & \multirow{2}{*}{5.16} & \multirow{2}{*}{0.39} & \multirow{2}{*}{$0.17-0.90$} & \multirow{2}{*}{0.23} \\
\hline Others & $16(61.5)$ & $10(38.5)$ & & & & \\
\hline \multicolumn{7}{|l|}{ Occupation } \\
\hline Housewife & $94(39.2)$ & $146(60.8)$ & \multirow{2}{*}{0.749} & \multirow{2}{*}{0.80} & \multirow{2}{*}{$0.48-1.32$} & \multirow{2}{*}{0.387} \\
\hline Others & $37(44.6)$ & $46(55.4)$ & & & & \\
\hline \multicolumn{7}{|c|}{ Educational Status } \\
\hline Up to SLC & $39(37.9)$ & $64(62.1)$ & \multirow{2}{*}{0.455} & \multirow{2}{*}{0.85} & \multirow{2}{*}{$0.52-1.37$} & \multirow{2}{*}{0.500} \\
\hline Above SLC & $92(41.8)$ & $128(58.2)$ & & & & \\
\hline \multicolumn{7}{|c|}{ Type of Delivery } \\
\hline Caesarian & $61(50.4)$ & $60(49.6)$ & \multirow{2}{*}{7.796} & \multirow{2}{*}{1.9} & \multirow{2}{*}{$1.21-3.03$} & \multirow{2}{*}{0.005} \\
\hline Vaginal & $70(34.7)$ & $132(65.3)$ & & & & \\
\hline
\end{tabular}

Table 7: Relationship between Knowledge and Practice of the Respondents about EBF $(n=323)$

\begin{tabular}{|c|c|c|}
\hline Knowledge and Practice & Correlation & $p$-value \\
\hline Knowledge & $0.14^{\text {a }}$ & 0.012 \\
\hline Practice & & \\
\hline
\end{tabular}

Note. aPearson's Correlation

\section{Discussion}

Regarding socio-demographic characteristics of the mothers of infants attending the immunization clinic, the mean age was $26.55( \pm 3.8$.). Hindus comprised of $92 \%$ of the respondents and $60.4 \%$ of the respondents belonged to Brahmin/Chhetri caste. More than $68.1 \%$ of the respondents had higher secondary level of education and $74.3 \%$ of the respondents were housewives. Almost all (98.5\%) of the respondents had hospital delivery and $62.5 \%$ of the respondents had vaginal delivery.

Regarding knowledge on initiation of breast feeding, $79.6 \%$ were aware of the initiation of breastfeeding within one hour of baby's birth. In contrast to study findings of Shrestha, Bhattarai, Silwal, $2013^{9}$ reported that $48 \%$ of the postnatal mother were aware of initiation of breastfeeding. In the same away practice regarding initiation of breastfeeding, $75.5 \%$ of the respondent's breastfed their children within one hour. Similar study finding of Ulak,Chandyo, Mellander, Shrestha and Strand $2012^{10}$, shows that $57 \%$ of the respondents were initiated breastfeeding within one hour of delivery. $\mathrm{NDHS}^{6}$ data showed that $45 \%$ mothers initiated breastfeeding within 1 hour of childbirth. Concerning colostrums feeding almost all (99.1\%) mothers were aware that colostrums should be fed to the baby. The study done by Joshi, Barakoti and Lamsal, $2012^{11}$ that $74 \%$ of the responded was aware about colostrums from various sources.

Regarding pre-lacteal feeding, $79.9 \%$ of the respondents correctly avoided giving pre-lacteal feeding to their babies. This finding is similar to that of Khanal, Adhikari, Sauer, and Zhao $2013^{12}$ where $73.5 \%$ of mothers reported of not giving prelacteal feeding to their newborn infants. Similar study done by Chaudhary, Shah and Raja $2011^{13}$ that $33 \%$ of the mothers gave the pre-lacteal feed to their babies.

More than half $(54.8 \%)$ of the respondents in this study had reported of giving breastfeeding to their infants "on demand" during the initial months. This finding is lower than that of the finding of study done by Chudasama, Patel, and Kavishwar, $2007^{14}$ as in their study it is reported that $80 \%$ women breastfed their children "On demand".

In this study most (84.5\%) mothers knew the correct meaning of EBF. This finding is similar to the findings of Afrosea, Banua, Ahmeda, and Khanoma ${ }^{15}$ as in their study the overall level of knowledge regarding breastfeeding among female garment workers is poor 
(88\%). Whereas Oche, Umar, Ahmed ${ }^{3}$ reported that only $31 \%$ of the mothers in their study had adequate knowledge of EBF. In the same way, Timilsina ${ }^{16}$ also reported that only 16.7 percent mothers had fair knowledge regarding the breast feeding.

Regarding practice of EBF, $49.5 \%$ of the respondents in this study practiced EBF up to 6 months as recommended by world health organization. According to Adhikari, Subedi, $2013^{17}$ showed that $34 \%$ of the responded practiced EBF upto six months. Another study done at Kanti Children's Nepal Hospital by Chapagain, $2013^{18}$ reported that $33 \%$ of the mothers were practiced exclusive breastfeeding. In contrast to this, the study finding of NDHS $(2011)^{6}$ revealed that $70 \%$ of children less than six months age were exclusively breastfed.

In this study, there was no significant association between respondent's level of knowledge regarding EBF with selected variables like, age, religion, ethnicity, occupation, and type of delivery. This finding is in accordance with that of Afrosea, Banua, Ahmeda, and Khanoma ${ }^{15}$ as in their study also no significant association was found between the knowledge score of breastfeeding with remaining socio-demographic variables like age, marital status.

But there was a significant association between respondent's level of knowledge regarding exclusive breast feeding and educational status ( $p=0.034$, OR $=1.7,95 \% \mathrm{Cl}=1.03-2.66)$. High level of knowledge regarding EBF was found among the respondents with educational status of above SLC (47.3\%) than respondents with educational status of up to SLC (44.7\%). Education was significantly $(p<0.001)$ associated with a higher total knowledge score of breastfeeding. Women with secondary level of education had a significantly higher $(p<0.001)$ level of total knowledge score than other categories (illiterate, primary and higher secondary) of education. Further the finding is supported by that of Timilsina, $2014^{16}$. But this finding is in opposite from that of Chudasama, Patel, Kavishwar, $2007^{14}$ as they reported that median duration of EBF was found more (7 months) for illiterate women than for literate (6 months).

Similarly, there was no significant association between respondent's level of practice regarding exclusive breast feeding with selected variables like, age, religion, ethnicity, occupation, educational status and type of delivery but there was significant association between respondent's level of practice regarding EBF and type of delivery $(p=0.005, \mathrm{OR}=1.9$,
95\% $\mathrm{Cl}=1.2-3)$. High level of practice regarding EBF was seen more among the respondents with vaginal delivery $(65.3 \%)$ than respondents with caesarian delivery (49.6\%).

This finding is supported by the study conducted by Onah et al., $2014^{19}$ as their study also revealed that mothers who delivered through caesarean section were 0.38 times less likely to exclusively breastfeed their newborn $(\mathrm{OR}=0.38,95 \% \mathrm{Cl}=0.18,0.84)$ compared to those who delivered vaginally. Similar finding reported by Zia, Rajieh, Mothhareh \& Ahmed, $2008^{20}$ where it was shown that the rate of EBF was significantly lower in the mothers delivered by caesarean section than who delivered vaginally ( $13.4 \%$ vs $41.8 \%$ ).

\section{Conclusion}

On the basis of the study findings, it is concluded that only about half of the mothers tended to have adequate knowledge as well as practice regarding exclusive breast feeding. The relationship between the knowledge and practice EBF seemed to be low. The level of knowledge regarding exclusive breast feeding tended to be higher among the mothers with higher education status. Similarly, the level of practice regarding exclusive breastfeeding tended to be higher among the mothers who had delivered vaginally.

Acknowledgements: I am thankful to Research Division, Tribhuvan University for providing grant and Institutional Review Board, Research Department of TU Institute of Medicine for ethical approval. I would like the extend my profound gratitude to Prof. Sarala Shrestha, Assistant Dean, Institute of Medicine, Prof. Dr. Sarala Joshi Head of Department, Education and Research, Nursing Campus Maharajgunj for their valuable suggestion and guidance to conduct this study. I am grateful to Assoc. Prof. Dr. Amod Kumar Poudyal Medical Campus, IOM Maharajgunj for statistical analysis and Ms Romina Shrestha Teaching Assistant, Nursing campus for data analysis.

Funding: This study is supported by Tribhuvan University, Research Division, Kritipur Kathmandu in the form of grant.

Conflict of Interest: None

Permission from IRB: Yes

\section{References}

1. WHO, UNICEF. Strengthening action to improve feeding of infants and young children 6-23 months of age in nutrition and child health programme. Report of Proceedings. Geneva. 6-9 Oct 2008. 
Available from: http://www.who.int/maternal_ child_adolescent/ documents/9789241597890/ en/.

2. Jones G, Steketee RW, Black RE, Bhutta ZA. Morris SS. How many child deaths can we prevent this year? Lancet 2003;362(9377):65-71.

3. Oche MO, Umar AS, Ahmed H. Knowledge and Practice of exclusive breastfeeding in Kware, Nigeria. Afr Health Sci J 2011;11(3):518-523.

4. WHO: Health topics. WHO 10 facts on breastfeeding. Available from: URL: http://www. who.int/features/factfiles/breastfeeding/en/ index.html

5. Sandra L, Huffiman SD, Elizabeth R, Zehner. Midwifery 2002;17(2):80-92.

6. Population Division Ministry of Health and Population. Nepal Demographic and Health Survey 2011. New ERA, ICF Macro; 2011.

7. Health Services Department. Annual Report 2011/2012.Kathamandu: Government of Nepal. Ministry of Health and Population.2012.

8. BPNI/IBFAN. Infant and Young Infant and young child feeding counseling: A training course the 4 in 1 course; an integrated course on Breastfeeding, Complementary feeding, Infant feeding, Infant Feeding \& HIV and Growth Monitoring-Counseling. Trainer's guide. 2013. Delhi India.

9. Shrestha T, Bhattarai SG, Silwal K. Knowledge and Practice of Postnatal Mother in Newborn Care. J Nepal Med Assoc 2013;52(6):190.

10. Ulak M, Chandyo RM, Mellander L, Shrestha PS, Strand TA. Infant feeding practices in Bhaktapur, Nepal: across-sectional, health facility based survey. Int Breastfeed J 2012;10(7):1

11. Joshi S, Barakoti B, Lamsal S. Colostrum Feeding: Knowledge, Attitude and Practice in Pregnant Women in a Teaching Hospital in Nepal. WebmedCentral:International Journal of Medicine and Molecular Medicine 2012;3(8):WMC003601

12. Khanal V, Adhikari M, Sauer K, Zhao Y, Egata G, Berhane Y, Worku A, Holbrook K, White M, Heyman $M$. Factors associated with the introduction of prelacteal feeds in Nepal: findings from the Nepal Demographic and Health Survey 2011. Int Breastfeed J 2013;1(8):9.

13. Chaudhary RN, Shah T, Raja S. Knowledge and Practice of Mothers regarding breastfeeding: a hospital based study. Health Renaissance 2011;9(3):194-200.

14. Chudasama R, Patel P, Kavishwar A. Factors Associated with Duration of Exclusive Breastfeeding. Internet J Pediatr Neonatol 2007;9(1). Available from: https://ispub.com/ IJPN/9/1/4871.

15. Afrosea L, Banua B, Kazi R, Ahmeda, Khanoma $\mathrm{K}$. Factors associated with knowledge about breastfeeding among female garment workers in Dhaka city. WHO South-East Asia J Public Health 2012;1(3):249-255

16. Timlsina S. Breastfeeding Knowledge and Practices among Mothers of Children under two years of age in Sarangkot VDC, Kaski Nepal. Abstract: First national Population Conferences. Institute for Social and Environmental Research Nepal. Available from: http://pannepal.org/ event/images/userfiles/files/Paper\%20607\%20 Subash\%20Timilsina.pdf

17. Adhikari T, Subedi I. Knowledge and Practice of Breastfeeding among Mothers of Infant. J Food Sci Technol Nepal 2013;8:71-74.

18. Chapagain RH. Complementary Feeding Practices of Nepali Mothers for 6 Months to 24 Months Children. J Nepal Med Assoc 2013;52(7)191.

19. Onah S, Ignatius D, Osuorah C, Ebenebe J, Ezechukwu C, Ekwochi U, Ndukwu I. Infant feeding practices and maternal socio-demographic factors that influence practice of exclusive breastfeeding among mothers in Nnewi South-East Nigeria: a cross-sectional and analytical study. Int Breastfeed J 2014;9:6. doi: 10.1186/1746-4358-9-6. eCollection 2014.

20. Zia I, Razieh F, Motahhareh G, Ahmed S. Relationship between Delivery type and Successful Breastfeeding. Iranian J Pediatr 2008;18(1):47-52. 